\title{
The Interpersonal Grid: I. Felt and tape techniques for the measurement of social relationships
}

GeORGE LEVINGER AND JEANMETTE GUNNER UNIVERSITY OF MASSACHUSETTS

The Interpersonal Grid is a new method for measuring social relationships. Two parallel techniques are described which enable one to obtain nonverbal ratio-scale measures along both the liking and the status dimensions.

This paper describes a new method for conceiving and measuring interpersonal relationships on a twodimensional ratio-scale grid. Foa (1961), Leary (1957), and various others have suggested that most aspects of social relationships can be described in terms of two orthogonal axes. The horizontal dimension would describe Love-Hate or approach-avoidance. The vertical dimension would refer to Dominance-Submission or high vs. low status.

The Interpersonal Grid provides a way of describing relationships along these two axes, adapting a figure placement technique introduced by Kuethe (1962) for the measurement of "social schemata." The original technique or variations have been used by Kuethe and by other investigators (e.g., Weinstein, 1965; Little, 1965; Carlson \& Price, 1966). In most of these previous studies, the $S$ has been asked to place pairs of silhouette figures (human or rectangle) cut out of felt material onto a large neutral felt background ". . in any manner you wish." Comparisons were then made of the relative horizontal distances between differing pairs of figures and between differing groups of Ss.

In an initial study of interpersonal distance (Levinger \& Gunner, 1966), we measured the horizontal distance between pairs of male-female figures as an index of intimacy. We discovered that Ss varied distances not only along the horizontal plane, but also conveyed information about their "schemata" by the relative vertical positions of the figures. It was decided, therefore, to incorporate both the horizontal and the vertical dimensions as the " $x, y$ coordinates" of what we now call the Interpersonal Grid.

The Felt Technique.

The first version of the Interpersonal Grid was a felt board, $2 \mathrm{ft} \times 3 \mathrm{ft}$ in area, mounted on a piece of Plexiglas which had a transparent two-dimensional grid glued to it. The $S$ who stands in front of it sees a felt background not too different from that seen by Kuethe's Ss; however, the $\mathrm{E}$ sitting behind the Plexiglas is able to make readings of figure placements directly through the felt board and plot S's responses in terms of the two-dimensional coordinates. Units are measured in tenths of inches, about the optimal precision obtainable with this method. Between trials $E$ can rapidily and precisely read off both the $x$ and the $y$ coordinates of the placed figures. The size of the felt figures is $8 \mathrm{in.high}$ $x 3$ in. wide; they are similar to Kuethe's (1962) figures, but are entirely symmetrical.

The Tape Technique.

While assembling the resources for constructing the transparent $2 \mathrm{ft}$ by $3 \mathrm{ft}$ grid, we discovered a new way of making miniature silhouette figures that would considerably simplify the collection of Interpersonal Grid data. Miniatures of the felt figures, 1 in. high $x 3 / 8$ in. wide, were reproduced in a sticky black material which has the same properties as masking tape. 2 The $S$ places these small figures on a neutral background consisting of an ordinary 8-1/2 in. $x 11$ in. sheet of white ditto paper. Although figures may be moved after being placed, their position on the ditto paper provides a permanent record. Thus positions of the figures on the paper can be scored later-after all S's placements have been completed and $E$ has returned home. In the Tape Technique the grid is a sheet of graph paper laid on top of an illuminated glass box; the light shines through the grid underlay, and the coordinates of the tape figures can easily be read off with a reliability approaching $100 \%$.

\section{Advantages of the new rechniques.}

Both the Felt and Tape Techniques provide more information and precision than previous methods of measuring social schemata. As in the earlier work, $S$ projects his "perceived structure of interpersonal relationships" upon a neutral background. Yet the grid enables $E(1)$ to read off information about two orthogonal dimensions, and (2) to take his readings precisely and without the delays attendant on Kuethe's (1962) technique. (3) Both techniques use the valuable ratio-scale feature implied, but not exploited, by the earlier investigations.

The Tape Technique offers interesting advantages over any felt method: (a) After each measurement on the felt board, the felt figures are of necessity removed. However, the inexpensive tape figures remain as placed; they constitute a permanent record, allow unhurried, highly reliable scoring, and can become part of a permanent record of an individual 
or group. (b) The paper booklets are, of course, more portable than a large felt board. In studies where it is necessary to bring stimulus material to the Ss, this technique is far more appropriate than a laboratory-based felt board. (c) Most useful, probably, is the fact that the Tape Technique facilitates group administration. Only one $S$ at a time can do the felt placements, but an indefinitely large number of Ss can simultaneously make tape placements. Group administration greatly reduces the cost of research on social schemata.

Under some conditions, however, the Felt Technique may have some advantages over the Tape Technique: (a) The figures are larger, and therefore easier to manipulate. One study of social schemata at the child guidance clinic of the University of Massachusetts is using the Felt Technique because the children can handle the larger figures more easily. (b) Also, whereas a limited number of predesigned dies would be available for the Tape Technique, any number and variation of felt figures can be designed and cut in a short space of time. (c) For some studies, it is advantageous for $E$ to collect data for only one $S$ at a time, and to sit behind the grid while $S$ makes his placements. For instance, if $E$ should try to condition $S$ to increase or decrease the inter-figure distances during a series of repeated placements, the Felt Technique would be more appropriate than the Tape version.

How closely correlated are placement disiances on the Felt and Tape Techniques?

In a methodological study, 48 Ss placed a series of male and female peer figures in relation to a stationary figure. Across the two techniques, there was a significant correlation between scores: For horizontal distances, mean $r$ was .51 ( $p<.01)$; for vertical distances, mean $r$ was $.30(p<.05)$. One reason for the lower vertical correlations is that the vertical distance varies very little from zero when peer relationships are examined. This study showed only a modest, but significant correspondence between the two techniques; further research on the reliability of the methods is required.

\section{Are the horizontal and vertical dimensions valid indicators} of positivify and status?

The Tape Technique was administered in a class of 35 students. Each $S$ had a booklet with 10 pages; on each page, a stationary figure was stuck in the exact center. For Trials 1-5, $S$ was asked to imagine that the stationary figure was himself; for Trials 6-10, the figure-to-be-placed was the self. In each series of five trials, the first two placements referred to an other who is "'. . a good friend, but not your best friend"-first a same-sex, then an opposite-sex friend. The next two trials referred to
". . another student on this campus, a stranger whom you've never met." The fifth trial in each series referred to ". - a typical professor at the University of Massachusetts." All the figures were the same male or female silhouettes used throughout our present research.

The findings confirm the meaningfulness of both the vertical and horizontal dimensions of measurement. On the vertical dimension, most placements of the friend and the stranger peer figures were on the same height as those of the S's self. In contrast, $71 \%$ of the placements of the professor figure put the professor above $S$.

Regarding the horizontal dimension, there were two sorts of validating evidence. First, the mean distance between self and friend was $20.9 \mathrm{~mm}$, for self-stranger it was $63.6 \mathrm{~mm}$, and for self-professor it was 40.5 $\mathrm{mm}$. There was not one overlap between friend and stranger distances, but distances from the professor varied widely.

Second, it was hypothesized that students who sit at the back of the classroom, and who typically are prone to sit at the back of other classrooms, would tend to place a greater distance between self and a professor than students sitting at the front. Comparing self-professor distances for the front and back halves of the class, this hypothesis was confirmed for the first placement trial $(t=2.31, p<.05)$, but the difference diminished on the second trial.

A variety of other applications are indicated for the Interpersonal Grid. Not only is it a handy tool for the study of relational ecology (Sommer, 1967), but it lends itself to easily replicable research on many of the central problems in social psychology.

\section{References}

Carlson, Rae, \& Price, Mary Ann. Generality of social schemas. J. Pers, soc. Psychol., 1966, 3, 589-592.

Foa, U. G. Convergences in the analysis of the structure of interpersonal behavior. Psychol. Rev., 1961, 68, 341-353.

Kuethe, J. L. Social schemas. J. abmorm. soc. Psychol., 1962, 64, 31-38.

Leary, T. Interpersonal diagnosis of personality. New York: Ronald, 1957.

Levinger, G., \& Gunner, Jeannette. Social schemata for male-female relationships. Unpublished paper, 1966.

Little, K. B. Personal space. J. exp. soc. Psychol., 1965, 1, 237247.

Sommer, R. Small group ecology. Psychol. Bull., 1967, 67, 145-152. Weinstein, Laura. Social schemata of emotionally disturbed boys. J. abnorm. Psychol., 1965, 70, 457-461.

\section{Notes}

1. The ideas were developed during an undergraduate project by J. G. with the guidance of G. L. Later work was supported by Grant CRD 249E-5-153 from the Welfare Administration.

2. The silhouettes were drawn by Elaine Himmelfarb; the tape miniatures are produced for us by Chart-Pak, Inc., Leeds, Mass. 